It is improbable that these are anything but a fraction of $\mathrm{Dr}$. Nicholson's etymological misrepresentations. Mistakes in the glossary of a zoological work are not of very great importance, and would not in this case have demanded notice had they mot been fair samples of the general character of the book in whicit: they occur.

I much regret that the fact of the writer's name being appended to the notice of Dr. Nicholson's work should have Ied him into the region of personalities, whither I do not intend to follow him.

E. RAY LANKESTER

\section{Glass Floats off the Isle of Lewis}

Ir would be of great importance if the fact could be ascertained whether the floats are from the Norwegian or from the Canadian fisheries. Your note of November Io says, "They are hermetically sealed, and have certain characters, such as IV. or VI., impressed on the sealed part." Doubtless your columns are read in Norway as well as in Canada, and possibly a correspondent, from these characters or from other evidence, may claim the floats for one or for the other side of the Atlantic. In favour of the zuest side, but with the utmost deference to the opinion of Mr. Gwyn Jeffreys, I suggest that a north-east wind is an unlikely conveyance to "the west side of the Island of Lewis," or to "the western coast of Shetland."

A writer in the Athenaum of this week (Nov. 19, p. 659) thinks that these "net floats" are carried to Nova Zembla, and "still farther to the north and east" by the Gulf Stream. Dr. Carpenter supposes a constant warm surface current from each tropic to each pole, and a constant cold current below from each pole to each tropic,caused as we cause the currents of water to warm our houses. Suppose this grand theory to be true. The surface current should warm east coasts as well as west coasts. The same parallel touches England, Newfoundland, and Vancouver's Island. The climate of England and of Vancouver's Island on west coasts is "insular." The climate of the island of Newfoundland on an east coast is "excessive." This difference of climate in islands, on the same parallel, at the same levels, results from currents of air, not from currents of zvater-namely, from the prevalence of south-west winds in the north temperate regions. In winter with a south-west wind we hunt, with a north-east wind we skate.

Brookwood Park, November 19.

George Greenwood, Colonel

\section{ENGLISH GOVERNMENT ECLIPSE EXPEDITION}

THESE arrangements and instructions are not yet finally completed, but it is thought that the latter may be useful to members of other Expeditions, though they are not yet by any means complete.

\section{A. SPANISH AND ALgERIAN PaRTy.}

NOTE. - his party leaves Portsmouth in the "Urgent," on the 6th proximo. Observers to be on bourd by 5 P. M. on the 5 th.

I. Cadiz Detachmenl.-In charge, the Rev. S. J. Perry. Spectroscope, the Rev. S. J. Perry and assistant (Mr. Hostage), Mr. Abbay; Polariscope, Mr. Moulton, Mr. Hudson: Sketches of Corona, Mr. Naftel, Mr. Smyth, Mr. Penrose, Mr. Collins; Time and General Observations, Captain 'Toynbee.

2. Gibraltar Detachment.- In charge, Captain Parsons. Spectroscope, Mr. Carpmael, Mr. Gordon; Polariscope, Mr. Lewis, Mr. Ladd; Photography, Mr. Buckingham, and assistant (Mr. Spiller); Sketches of Corona, Mr. Hunter, two Oxford men; Saturn in the Corona, Mr. Talmage, Mr. Maclear; Chemical Intensity, Mr. Thorpe. 3. Oran Detachment-In charge, Mr. Huggins. Mr. Huggins, Admiral Ommanney, Rev. F. Howlett, Mr. Carpenter, Mr. Crookes, Captain Noble, Dr. Gladstone, Prof. 'Tyndall.

\section{B. SicIlian PARTy.}

Note.- This Party leaves London, overland, at 8.45 P.M. from Charing Cross, on the $7^{\text {th }}$ proximo.

In charge, Mr. Lockyer. Spectroscope, Mr. Lockyer and assistant (Mrs. Lockyer), Prof. Roscoe and assistant (Mrs.
Bowen), Mr. Seabroke and assistant (Mr. Burton), Mr. Pedlar; Polariscope, Mr. Raynard, Mr. Griffith, Mr. Clifford; Sketches of Corona, Mr. Brett, Mr. Darwin; Photography, Mr. Brothers, Herr Vogel, Mr. Harris; Time and General Observations, Mr. Vignoles, Sen., Mr. Vignolles, Jun.

\section{INSTRUCTIONS TO OBSERVERS.}

Instructions for the Polariscopic Observations of the Corona, including Beams and Streamers.-It is recommended that the polariscopic examination of the Corona be carried on as follows :-

I. To examine a detached and selected part of the Corona about $6^{\prime}$ from the limb of the sun, and say about $8^{\prime}$ in diameter. 2. A field extending from the limb of the sun outwards should be examined either with a Nicol's prism, or a double image-prism. 3. The light of the streamers at some distance from the sun should be examined with a Nicol and a crystal, 4. The polarisation of the Corona should be examined in such a manner as to eliminate atmospheric polarisation. Note.-The most suitable instruments for ascertaining the plane of polarisation, and the proportion of polarised to unpolarised light are (I) a double-image prism; (2) Savart's polariscope; (3) a plate of quartz, consisting of two compensation wedges turned through an angle of $180^{\circ} ;(4)$ a plate of arragonite, or calc spar, cut perpendicular to an optic axis, and affixed to an analysing prism ; $(5)$ a polarimeter, consisting of four plates of glass, movable on an axis perpendicular to the plane of polarisation.

First Observation.-The object of this observation is to observe the polarisation (if any) of the Corona without having the observer's attention distracted by the chromosphere. A Savart's polariscope is recommended by preference. The Nicol's prism of the polariscope should be set beforehand with its principal plane (or plane of symmetry) radial, i.e. perpendicutar to the sun's limb, and the observer must note whether bands are visible, and if so, whether they are black-centred or white-centred. Should the bands be feeble, it will be well to rotate the polariscope, prism and plates of course moving together, and quickly restore it to its primitive azimuth, after having noted the estimated azimuth of the Nicol when the bands are strongest and black-centred. Should no bands, or only dilute bands be seen, it may be that the Corona, though polarised, is overpowered by other light; and the observer will move the telescope from the sun, radially if it may be, if in any other direction rotating the polariscope so as to render its principal plane radial in the new position. He will then note whether, though the light becomes feebler, the bands become less dilute. Should, on the other hand, the bands be strong, the observer, after having satisfied himself as to the plane of polarisation, will endeavour to make out whether by means of the polarisation of its light the Corona can be detected superposed on the chromosphere. He will, therefore, move the telescope torvards the sun, keeping the principal plane of the polariscope radial, and note how near the sun the bands can still be seen. To provide for the contingency of this observation, it will be well to point in the first instance to the side of the sun which will be first uncovered. If time permit he should try whether there is any sensible quantity of polarised light on the dark disk of the moon, rotating the analyser and determinating the plane of polarisation.

Second Observation. - The special object of this observation is to differentiate, if possible, between the Corona, on the one hand, and the Chromosphere, or whatever else may be self-luminous (be it even a portion of the Corona itself), on the other. This will'be possible if the light of the Corona be strongly polarised, so as to admit of com. parative extinction by an analyser. The observer should turn the analyser so as to extinguish, as far as may be, the light of the Corona in the neighbourhood of a radius 